\title{
OLAVO BILAC, CRONISTA DOS TEMPOS MODERNOS
}

\author{
Marta Scherer \\ Doutoranda em Literatura - UFSC
}

\begin{abstract}
RESUMO
Este artigo pretende lançar ao debate o papel de Olavo Bilac como cronista moderno, apontando como sua escrita e postura fizeram do 'poeta das estrelas' um jornalista das calçadas. Através de seus textos em crônica é possível vislumbrar o impacto que a modernização e os ideais de modernidade, tal como apreendidas e apresentadas por Olavo Bilac, produziram na sociedade e no imaginário daquelas gentes que viviam o limiar entre os séculos XIX e XX. Demonstrar a mentalidade e a escrita de Olavo Bilac é objetivo deste texto, que busca também pensar as transformações relativas à vida urbana e aos meios de comunicação com a chegada dos 'tempos modernos' ao país.
\end{abstract}

PALAVRAS- CHAVE

Olavo Bilac; Crônica; Modernidade

\section{OLAVO BILAC, A CHRONIC WRITER FROM THE MODERN TIMES}

\begin{abstract}
This paper aims to debate Olavo Bilac as a modern chronic writer, pointing out how his written style made him a "journalist of the streets" out of a "poet of the starts". Through his chronicles it is possible to perceive how the impact caused by modernization and modern model, as captured by Olavo Bilac, affected society and people minds from the $19^{\text {th }}$ and $20^{\text {th }}$ Centuries. Demonstrating Olavo Bilac's modern style and mentality is a way to think about urban and communication changes and how they were affected by the "modern thinking" in Brazil
\end{abstract}

KEYWORDS

Olavo Bilac; Chronicle; Modernity 
Era uma bela manhã de domingo. Apesar do calor, homens de casaca e mulheres com a cabeça coberta se dirigiam para a missa. Nas ruas os bondes elétricos ajudavam os que tinham pressa em rezar ou visitar os parentes. As famílias colocavam suas melhores roupas e contratavam fotógrafos para registrar momentos solenes. Em algum café os homens reunidos discutiam a crônica semanal de um dos dez jornais que circulavam no Rio de Janeiro, ali, em 1901.

De repente, um veloz e surpreendente "monstro que tinha fornalha, caldeira, chaminé, grelha, correntes, ganchos, um inferno!"1 irrompe no meio da rua, passa pela Rua do Catete arrancando paralelepípedos, perde o controle lá para os lados da Tijuca e vai de encontro a um barranco. Era o primeiro automóvel que circulava por ruas brasileiras, de propriedade daquele que viria a ser chamado de 'pai da abolição', José do Patrocínio, que nessa manhã de domingo ocupava o banco de passageiro. Na direção, Olavo Bilac, o 'poeta das estrelas', jornalista das calçadas, cidadão dos novos tempos.

Quando as máquinas tomaram também conta das ruas - depois da instalação do bonde, um ícone do progresso, os automóveis chegaram devagar, mas já deslumbrando José do Patrocínio importou o primeiro carro a circular na jovem Capital Federal. Em livro biográfico sobre Paula Ney, Raimundo de Menezes conta que um grupo de amigos de Patrocínio passou a noite de sábado em claro em torno do "monstro". Mas, na hora de subir a bordo, "todos tiraram o corpo. Só Olavo Bilac, afoitadamente, deu um passo à frente e subiu para a boléia ${ }^{2}$ ". A aventura com o primeiro automóvel a rodar no Brasil a menos de cinco quilômetros por hora - foi assim relatada por Coelho Neto:

\footnotetext{
Ia de encontro às árvores e escorchava-as, derrubava combustores, trepava nas calçadas, urrando, faiscando; investia com os bondes cujos passageiros fugiam aos berros, atirava marradas aos portões arrombando-os. Às vezes empacava arquejando, aos estouros, como se fosse rebentar. Os animais dos carros disparavam espavoridos e nos vãos das portas, as crianças levantavam clamores de susto, nem foi tamanho o terror entre os homens quando Faetonte tomou o governo do carro do sol". 3
}

O episódio serve como exemplo das contradições experimentadas por quem viveu a chegada dos 'fabulosos tempos modernos' ao Brasil. Mais que uma anedota, torna-se paradigma de um momento e coloca em cena um dos seus personagens mais

\footnotetext{
${ }^{1}$ MENEZES, Raimundo de. A vida boêmia de Paula Ney. 3 aed. São Paulo: Martins Editora, 1957, p.84

${ }^{2}$ MENEZES, Raimundo de. A vida boêmia de Paula Ney. Op.cit., p. 85

${ }^{3}$ Citado por: MENEZES, Raimundo de. A vida boêmia de Paula Ney. Op.cit., p.85
} 
atuantes: Olavo Bilac. Inserido de forma contundente na Belle Époque brasileira, Bilac vivenciou como poucos o momento de transição nacional no virar de séculos e foi um observador da 'modernidade' que se instalava no país.

O automóvel aqui já se configura como um ícone. A própria Avenida Central, símbolo maior da reformulação urbana na paisagem carioca na passagem do XIX para o XX, foi idealizada para que nela somente os carros pudessem circular $^{4}$. Não contava com trilhos de bonde e o calçamento em macadame foi projetado em prol do símbolo máximo do novo século, o automóvel. Entretanto, em 1905, data de inauguração da Avenida, somente seis dessas máquinas circulavam pelas ruas da Capital Federal.

Não é por acaso que Olavo Bilac protagonizou a chegada do automóvel ao Brasil. Até mesmo a revista que o coroou como 'príncipe dos poetas' trazia no título o "Fom Fom" que caracterizava o símbolo da novidade. Moderno como Bilac. Defensor extremado do progresso, da tecnologia, das reformas urbanas de sua época, entusiasta do bota-abaixo carioca, admirador da dupla - a la francesa - Rodrigues Alves e Pereira Passos - foi um homem do seu tempo, vivendo-o de forma intensa.

Apesar de ter entrado para o cânone literário como o grande poeta parnasiano, foi nos seus textos em crônica, escritos ao longo de duas décadas, que deixou registros das transformações que a cidade e a população do Rio de Janeiro experimentavam em clima de Belle Époque. Seu trabalho como jornalista somente há pouco veio à luz, através da monumental pesquisa do professor Antônio Dimas, que organizou, recuperou, valorizou e trouxe à luz centenas de crônicas bilaquianas ${ }^{5}$, incorporando este outro Bilac à história literária desde então, seja através dos ensaios que mostram o jornalista atuante e intelectual ativo, seja por meio dos textos que transcreveu e/ou catalogou. Com mais do que conhecimento de causa, o professor Dimas comprovou que os mais variados temas foram comentados por Bilac, que encontrou nos periódicos um caminho para expor suas impressões:

Nesses quase vinte anos de jornalismo diário, muitas vezes espalhado por mais de um veículo, seu posto privilegiado permitiu-lhe uma visão angular da sociedade, cujas frinchas e reentrâncias dificilmente escapavam ao seu olhar bisbilhoteiro e nem sempre certeiro. Ideologicamente irregulares como

\footnotetext{
${ }^{4}$ ESSUS, Ana Maria Mauad de Souza Andrade. O espelho do poder: fotografia, sociabilidade urbana $e$ representação simbólica do poder político no Rio de Janeiro da Belle Époque. In: SOUZA, Célia Ferraz de; Pesavento, Sandra Jathay (org). Imagens urbanas: os diversos olhares na formação do imaginário urbano. Porto Alegre: Editora da Universidade, 1997. p.287.

${ }^{5}$ A antologia Bilac, O Jornalista (São Paulo: Imesp, 2006) é o resultado do trabalho de pesquisa de mais de 20 anos do professor Dimas e que culminou em sua tese de livre docência e que, posteriormente, no ano de 2006, foi lançada em livro.
} 
é de se esperar de quem não se pautava por um credo único, religioso ou político, as crônicas de Bilac pouco atraem aqueles que precisam de posições alheias para confirmar as suas. Mais que escora, elas se prestam ao investigador minucioso que esteja preocupado com uma visão mais abrangente de dado período. Porque, nelas, o material é farto. ${ }^{6}$

A imprensa não só foi central na vida do autor, como também deu vazão a uma obra diferenciada, já que, como afirmou Jefrey Needell, “em sua escrita, Bilac mantinha uma dualidade. Na época, sua poesia já saíra de moda na França, mas sua prosa estava bem no compasso das novidades" "7. Dessa forma, se o parnasianismo o marcou como um poeta tradicional, sua extensa prosa colocou o autor no rigor do que estava em voga.

Olavo Bilac encontrou nas páginas dos jornais as companheiras ideais para vivenciar as transformações de um país que se modernizava. Entre centenas de periódicos publicados na então Capital Federal e na emergente São Paulo, em quase todos encontramos a colaboração do cronista. Mais do que uma profissão, o jornalismo era uma paixão de Olavo $\mathrm{Bilac}^{8}$, como descreveu em texto em que recordava como se desenrolaram suas atividades na imprensa:

\begin{abstract}
Um pobre rabiscador de crônicas principia a escrever uma seção diária, numa folha, por necessidade ou por desfastio; dentro de poucos meses, já a escreve por gosto; e dentro de menos de dois anos, escreve-a por paixão - por uma dessas paixões que são feitas ao mesmo tempo de amor e de hábito, de prazer e de vício, de revolta e de ciúme, - cativeiro voluntário, que o cativo às vezes amaldiçoa, mas do qual não se quer libertar. ${ }^{9}$
\end{abstract}

A trajetória deste Olavo Bilac acompanhou as mudanças no país. Quando o Brasil vivia a Abolição da escravatura e a proclamação da República, era boêmio e revolucionário. Nos atribulados anos de implementação do novo sistema, foi contestador e político, no auge da Belle Époque, foi um entusiasta. Vivia, sem dúvida, as incoerências de cada momento, e "o trabalho que empreende, desta forma, afina-se com a mais pura tradição da modernidade, compreendida por campo de tensões e

\footnotetext{
${ }^{6}$ DIMAS, Antonio (Org.) . Vossa Insolência. Crônicas de O. Bilac. São Paulo: Companhia das Letras, 1996, p.14

7 NEEDELL, Jeffrey. Belle Époque Tropical: sociedade e cultura de elite na virada do século. São Paulo: Companhia das Letras, 1993, p.243

${ }^{8}$ Em minha dissertação, orientada pelo professor Carlos Capela e defendida em fevereiro de 2008 no Programa de Pós-Graduação em Literatura da Universidade Federal de Santa Catarina, em cuja banca tive o privilégio de contar com os professores Antonio Dimas e Maria Lúcia Carmargo, tracei a trajetória deste Bilac jornalista e, através dos seus textos, revivi esse importante período da história da imprensa brasileira.

${ }^{9}$ BILAC, Olavo. Registro. A Notícia. 17/09/1906, p2, 1 col. In: SIMÕES JR., A. S. A sátira do parnaso. Tese de Doutorado. PPGL. Assis: UNESP, 2001, p.56
} 


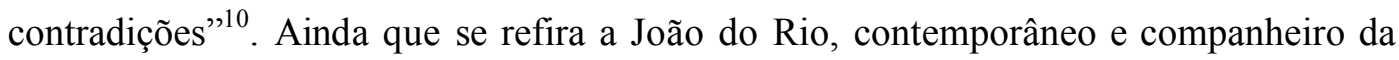
Belle Époque, a afirmação do professor Carlos Capela poderia muito bem ter sido formulado para a vida de Olavo Bilac, cuja carreira foi composta de diversas facetas. Transgressor quando jovem, parnasiano na poesia, polêmico na imprensa, burocrata no serviço público. Um príncipe que inspecionava escolas. Ourives na poesia, produziu obras didáticas, elaborou reclames, escreveu na imprensa, realizou conferências. O certo é que tinha como traço fundamental de sua personalidade o papel de comunicador, deixando um legado de quem dominou a escrita, absorveu e assumiu as posições e correntes de sua conturbada época. Com uma eloqüência caracterizada como “irresistível” por Antônio Candido, o escritor era amado e idolatrado.

Dos versos idealizados na solidão da escrivaninha à crônica redigida no tumulto da redação encontra-se o movimento desse intelectual, que sai de dentro de casa para observar as ruas, que vai do livro para o jornal, dos corações partidos para as reformas urbanas. Segundo Luís Augusto Fischer, foi nas crônicas que Bilac aderiu completamente ao "ritmo frenético de seu tempo" ${ }^{11}$. O homem que se tornou sucesso de público aos 23 anos com seu livro "Poesias" praticamente deixou de lado o fazer poético $^{12}$ para dedicar-se ao jornalismo, com a naturalidade de quem observa, constata, absorve, introjeta e registra a modernidade incipiente. Como recentemente analisou Luis Augusto Fischer, os poetas dessa geração foram intelectuais ativos:

Ao poeta proscrito e exilado sobrepõe-se, com Bilac e seus pares, o poeta que intui sua função no mundo moderno: o mundo da representação que, um século depois de iniciar-se, chega flamante e exacerbado a nossos dias. $\mathrm{Na}$ soleira desse nosso mundo, inaugurado pelos eufóricos parnasianos da belle époque carioca, o poeta é o escritor que reivindica pagamento, que fala da profissionalização, que funda associações e academias.

Em uma palavra: gramscianamente orgânico, o parnasiano é um escritor que vai á luta. Trabalha e teima e lima e sofre e sua não apenas nos catorze apertados versos de um soneto, mas sobretudo no nada estéril turbilhão da rua. 13

10 CAPELA, Carlos Eduardo S. Um rio excelso, o rio do excesso. DOMINGOS, Chirley; ALVES, Marcelo (orgs). A cidade escrita - literatura, jornalismo e modernidade em João do Rio. Itajaí: Universidade do Vale do Itajaí, 2005, p. 157

${ }^{11}$ FISCHER, Luís Augusto. Parnasianismo brasileiro: entre ressonância e dissonância. Porto Alegre: Edipucrs, 2003. p.89

${ }^{12}$ Depois do estrondoso sucesso de sua primeira publicação, em 1888, Bilac a reedita aumentada em 1902 e lança um livro de poesias infantis em 1904. Para aquele que foi considerado um "príncipe" não é uma produção extensa. Ao longo da vida publica poemas em jornais, mas em pouca quantidade. Muitos foram editado na obra póstuma "Tarde".

${ }^{13}$ FISCHER, Luís Augusto. Parnasianismo brasileiro: entre ressonância e dissonância. op.cit. p.8 
Olavo Bilac foi um dos mais atuantes exemplos dessa categoria de escritores jornalistas. Da imprensa, muito mais que dos cargos públicos, obteve seus recursos econômicos permanentes. Jornalista de crônicas diárias ou semanais, acompanhou e testemunhou a transformação das tediosas folhas doutrinárias nos primeiros jornais modernos; a aparição da informação gráfica 'ameaçando' a palavra escrita; a irrupção toda poderosa da "notícia" como labor das agências informativas; o surgimento do critério de 'novidade' e do 'sensacionalismo'. Chegou inclusive a perceber o ofuscamento crescente do escritor pelo novíssimo especialista que surgia, o repórter, uma figura nascida do jornalismo norte-americano. Viu - e deixou registro - sobretudo das transformações que a Capital Federal, suas ruas e suas gentes sofriam naquele virar de séculos:

\begin{abstract}
Daqui a pouco tempo, dentro de dois anos, quando a Avenida Central e a Avenida Beira-Mar estiverem concluídas; quando o Rio de Janeiro se encher de carruagens e de automóveis; quando começarmos a possuir a vida civilizada e elegante que Buenos Aires já há tantos anos possui -, também nessa época já não nos lembraremos do que era a nossa vida tediosa e vazia, sem teatros, sem passeios, de distrações limitadas à maledicência dos homens na rua do Ouvidor e à pasmaceira das senhoras nas janelas. ${ }^{14}$
\end{abstract}

Entretanto, exceto pelas pesquisas já citadas e poucas outras, até hoje a história literária brasileira tem concentrado sua atenção basicamente nas poesias do escritor. Apesar da importância dos textos jornalísticos para compreender uma etapa fundamental da cultura e da sociedade brasileiras, o desinteresse por grande parte da crítica fez com que a obra bilaquiana ficasse restrita ao campo da poesia parnasiana, nada mais. A crítica tradicional vislumbrou a obra de muitos autores - Olavo Bilac entre eles - de forma linear, através de elementos formais e estéticos, reduzindo a um denominador comum uma produção prolífera. O mesmo acontece com outros autores e em diferentes países - podemos citar Ruben Darío ou José Martí como os mais exponenciais - como se a produção em prosa não fosse digna de nota. Talvez por ser feita 'às pressas', talvez por ser remunerada.

A opção pelo jornalismo, sem dúvida, era econômica, mas praticamente inevitável. Ruben Darío deixou testemunho dessa condição em texto que fala de Francisco Contreras, chileno radicado em Paris que posteriormente foi colaborador da

\footnotetext{
${ }^{14}$ BILAC, Olavo. Chronica. Gazeta de Notícias. Rio de Janeiro, 15/01/1905. . In: DIMAS, Antônio. Bilac, o Jornalista: crônicas. v.1. op. cit., p.683
} 
antológica revista Martin Fierro: "como todos los que no gozamos de rentas produzidas por grandes capitales y tenemos que sacar del cerébro para nuestros lujos, caprichos, vicios o simples y precisos elementos de la existéncia, se ha dedicado al periodismo" ${ }^{15}$.

Com os empregos públicos não bastando para viver, era através do jornalismo que muitos autores podiam aumentar seus rendimentos valendo-se de sua condição de escritor. Em sua maioria trabalhavam como cronistas, escrevendo textos intermediários entre informativos e opinativos, casando fatos e comentários. Redigiam - muitas vezes em um mesmo texto - notas amenas, comentários da atualidade, colunismo social, crítica de arte, de teatro e de literatura, perfis de personagens célebres ou anônimos, descrições de viagem, descobertas científicas. Como bem descreve Olavo Bilac, era quase uma atividade mascate:

\begin{abstract}
Os cronistas são como bufarinheiros, que levam dentro das suas caixas rosários e alfinetes, fazendas e botões, sabonetes e sapatos, louças e agulhas, imagens de santos e baralhos de cartas, remédios para a alma e remédios para os calos, breves e pomadas, elixires e dedais. De tudo há de contar um pouco, esta caixa da Crônica: sortimento para gente séria e sortimento para gente fútil, um pouco de política para quem só lê os resumos dos debates do Congresso, e um pouco de carnaval para quem só acha prazer na leitura das seções carnavalescas. Aqui está a caixa do bufarinheiro, leitor amigo: mete dentro dela a tua mão e serve-te à vontade. Não fui eu quem a encheu de tantas coisas desencontradas e opostas. $\mathrm{Eu}$ sou apenas o retalhista, o varejista dos assuntos. Quem me enche a caixa é a Vida, a fornecedora dos cronistas. $^{16}$
\end{abstract}

Dessa maneira, foi através das letras impressas nos jornais, mais do que da poesia, que alguns autores da época - e não só brasileiros - dialogaram com o mundo moderno. Olavo Bilac era um desses homens, incorporando na sua vida e escritura intensamente as contradições do momento, em que, nas palavras do precursor José Martí:

As idéias não fazem família na mente, como antes, nem casa, nem longa vida. Nascem a cavalo, montadas em relâmpagos, com asas. (...) Com um problema nos levantamos; nos deitamos já com outro. As imagens se devoram na mente. Não chega o tempo para dar forma ao que se pensa. Perdem-se umas em outras as idéias no mar mental, como quando uma pedra fere a água azul, se perdem uns nos outros os círculos da água. ${ }^{17}$

15 DARIO, Ruben. Letras Chilenas. Obras completas. Madrid, Afrodisio Aguado, 1950, tomo II, p.635. In: RAMA, Angel. Ruben Dario y el modernismo. Caracas: Alfadil, 1985. p. 69

${ }^{16}$ BILAC, Olavo. Crônica.Gazeta de Notícias. Rio de Janeiro, 07/02/1904. In: DIMAS, Antônio. Bilac, o Jornalista: crônicas. v.1. op. cit., p.631

17 CHIAMPI, Irlema (coord). Fundadores da Modernidade. São Paulo: Editora Ática, 1991. p.199

Anuário de Literatura, ISSNe: 2175-7917, vol. 14, n. 1, 2009, p. 94 
A bela descrição do herói cubano mostra como a modernidade surge no cenário latino. Por modernidade entende-se essa crise de paradigmas que surge do desafio de conviver com o diferente e com a multiplicidade de versões. E, ainda, como escreveu Baudelaire em seu famoso artigo "Sobre a Modernidade", de 1863, "é o transitório, o efêmero, o contingente; é uma metade da arte, sendo a outra o eterno e o imutável". ${ }^{18}$ Assim, surge como sentimento, sensação, postura estética e mentalidade, traduz-se pela noção de exigência: é preciso 'ser do seu tempo', acompanhar o ritmo da história, 'captar a mudança e mudar com ela', como ação e pensamento. Esse aspecto dialético do movimento é captado por muitos dos escritores daquele momento e analisado por Marshall Berman com precisão quando profere sua conhecida sentença: "ser moderno é viver uma vida de paradoxo e contradição (...) é fazer parte de um universo no qual, como disse Marx, 'tudo que é sólido desmancha no ar"19.

O presente é o tempo da modernidade, que faz do agora sua própria consciência, "num movimento perpétuo e irresistível de uma modernidade escrava do tempo e devorando-se a si mesma, (...) renovada incessantemente e negando a novidade do ontem" ${ }^{\prime 20}$. Adiantados os ponteiros, eram comuns expressões que anunciavam que o futuro 'já tinha chegado' no virar dos séculos XIX para XX, uma época de efervescência cultural e econômica, marcada pela crença no progresso e na ciência, quando a civilização se impôs como um caminho sem volta.

O ritmo frenético das mudanças - seja na política ou na economia - fez com que a sociedade sentisse a necessidade de se modernizar, ainda que muitos nem entendessem o que exatamente isso queria dizer. "A vida moderna é feita de relâmpagos no cérebo e de rufos de febre no sangre", afirmou Bilac ${ }^{21}$, espantado com o fato de que "os homens de hoje são forçados a pensar e a executar, em um minuto, o que seus avós pensavam e executavam em uma hora”. É a época da entrada na modernidade de uma parcela da sociedade brasileira, enquanto a maioria da população vivia um atraso substancial. Tal dualidade mostra que também aqui foi "desta profunda

\footnotetext{
${ }^{18}$ BAUDELAIRE, Charles. Sobre a modernidade. $3^{\mathrm{a}}$ ed. Rio de Janeiro: Paz e Terra, 2002, p. 25

${ }^{19}$ BERMAN, Marshall. Tudo que é sólido desmancha no ar: a aventura da modernidade. São Paulo. Cia das Letras, 1986. p.15

${ }^{20}$ COMPAGNON, Antoine. Os cinco paradoxos da modernidade. Belo Horizonte: Editora da UFMG, 1996, p.25

${ }^{21}$ Citado por: SEVCENKO, Nicolau. Literatura como Missão. São Paulo, Brasiliense, 1989, p. 27
} 
dicotomia, dessa sensação de viver em dois mundos simultaneamente que emerge e se desdobra a idéia de modernismo e modernização"22.

As mudanças são abruptas, dentro de dois mundos que convivem num mesmo espaço físico complexo, favorecendo os duplos em diversas esferas da vida social, já que a entrada do país nos "tempos modernos" foi realizada através de um processo intrincado e ambíguo. Nas primeiras décadas do século XX acelerou-se a industrialização, a urbanização, o crescimento do proletariado e do empresariado. De outro lado, permaneceram a tradição colonialista, os latifúndios, o sistema oligárquico, o desenvolvimento desigual das regiões.

A ‘entrada na modernidade' somente ocorre pelo porto do Rio de Janeiro e pelos mais de quinhentos mil habitantes que vivem na cidade em 1890, número que dobra até 1920. É a partir dela e deles que se desenvolverão mudanças fundamentais no conceito de civilidade, de vida urbana e social. A maior cidade do país, terceiro porto americano em volume de comércio, superado apenas por Nova Iorque e Buenos Aires, serve como paradigma para todo Brasil, da mesma forma que Paris era o modelo a ser seguido pelas capitais americanas. Para imitar a capital francesa, é preciso realizar reformas urbanas, sonho da elite - letrada ou não - que desejava 'civilizar-se'. Comentando sobre o botaabaixo, escreve um animado Bilac:

\begin{abstract}
Há poucos dias, as picaretas, entoando um hino jubiloso, iniciaram os trabalhos da construção da Avenida Central, pondo abaixo as primeiras casas condenadas (...) No aluir das paredes, no ruir das pedras, no esfarelar do barro, havia um longo gemido. Era o gemido soturno e lamentoso do Passado, do Atraso, do Opróbrio. A cidade colonial, imunda, retrógrada, emperrada nas suas velhas tradições, estava soluçando no soluçar daqueles apodrecidos materiais que desabavam. Mas o hino claro das picaretas abafava esse protesto impotente. Com que alegria cantavam elas, as picaretas regeneradoras! $\mathrm{E}$ como as almas dos que ali estavam compreendiam bem o que elas diziam, no seu clamor incessante e rítmico, celebrando a vitória da higiene, do bom gosto e da arte! ${ }^{23}$
\end{abstract}

A nova e moderna Paris era imitada com deferência, com mesmo algum complexo de inferioridade diante da metrópole por excelência, da 'cidade luz' do século que glorificava a razão. Nas palavras de Olavo Bilac, “ Livre-me Deus da pretensão de querer comparar o Rio de Janeiro a Paris... Paris é Paris: e não sei se existe atualmente ou se haverá ainda, na face da Terra, alguma cidade que se lhe compare ou que se lhe

\footnotetext{
${ }^{22}$ BERMAN, Marshall. Tudo que é sólido desmancha no ar - a aventura da modernidade. São Paulo: Companhia das Letras, 2000, p.16

${ }^{23}$ BILAC, Olavo. Crônica.Kosmos. Rio de Janeiro, março de 1904. In: DIMAS, Antônio. Bilac, o Jornalista: crônicas. v.2. op. cit., p.337
} 
possa algum dia comparar" ${ }^{\text {24 }}$. O 'caso parisiense' mostra ser a cidade o espaço e o tempo de realização da modernidade", afirma Sandra Pessavento, ao mostrar que a referência de identidade faz com que,

\begin{abstract}
No primeiro dos exemplos escolhidos - a cidade do Rio de Janeiro - a sedução por Paris obedece à captação de uma coerência de sentido, no qual a adoção do 'modelo parisiense' é 'sintoma' da modernidade desejada a representa a possibilidade de assumir um padrão identitário que, metominicamente, passa da cidade para o país. Ocorre o que se pode chamar de metaforização do social, processo que implica a desterritorialização/ historicização de ações e discursos que, ao se deslocarem no tempo e no espaço, assumem novos significados. ${ }^{25}$
\end{abstract}

Imperava na sociedade um sentimento - muitas vezes não percebido de forma objetiva - de mudança, da transformação constante do espaço e dos conhecimentos, da matéria, dos êxitos da civilização e das façanhas humanas. Embora o Rio de Janeiro não apresentasse as condições que hoje conhecemos como as de uma metrópole, as pessoas sentiam-se como cidadãs cosmopolitas. Como bem define Walter Benjamin, é uma "sensação de modernidade ${ }^{26 "}$ " conquistada através da experiência do choque e ao custo, no caso da arte, da perda da aura. E aqui detectamos mais uma vez a modernidade, como a identifica Berman, quando a apresenta como experiência histórica, pessoal e coletiva, de sentir-se num mundo em transformação e mudar com ele.

Ainda que a industrialização somente se consolide no país em meados do século $\mathrm{XX}$, fatores como o fluxo de informações, a violenta urbanização, a imigração e os avanços tecnológicos fizeram com que os habitantes do Rio de Janeiro vivessem um estado de euforia modernizadora. Olavo Bilac foi um entusiasta desses tempos modernos, ao mesmo tempo que os temia. Em crônica de 1906 escreveu que "o progresso, porém, é como o apetite, que vient en mangeant", alertando que "o progresso é uma lei fatal! - Fatalíssima!” e que a falta de limites das inovações podiam fazer com que "os adoradores da velocidade cheguem ao absurdo e monstruoso resultado de chegar ao ponto de chegada antes de haver saído do ponto de partida!”. Concluiu seu texto refletindo sobre o futuro da humanidade que se precipita ao querer

\footnotetext{
${ }^{24}$ BILAC, Olavo. Crônica.Kosmos. Rio de Janeiro, janeiro de 1905. In: DIMAS, Antônio. Bilac, o Jornalista: crônicas. v.2. op. cit., p.338

25 PESAVENTO, Sandra. O imaginário da cidade: visões literárias do urbano - Paris, Rio de Janeiro, Porto Alegre. $2^{a}$ ed. Porto Alegre: Ed. Universidade/UFRGS, 2002. p.24

${ }^{26}$ BENJAMIN, Walter. A modernidade e os modernos. Rio de Janeiro: Editora Tempo Brasileiro, 1975. p.70
} 
inverter as regras físicas e morais, pois “o progresso é grande cousa, - mas é preciso que não se transforme em loucura"27.

Nessa fase, como explica Beatriz Sarlo ${ }^{28}$, "a cidade é vivida a uma velocidade sem precedentes, e as conseqüências desses deslocamentos rápidos não são apenas funcionais. A experiência e a luz modulam um novo elenco de imagens e percepções". ${ }^{29}$ É possível hoje resgatar parte desse sentimento através das representações escritas do urbano, acompanhando pelos olhos dos escritores os traços que caracterizavam essa modernidade. Pois, se a cidade era o palco da modernidade, o jornal era seu meio, fornecendo coordenadas para sua tradução em palavras $\mathrm{O}$ desenvolvimento da classe média e da vida burguesa no país propiciava o incremento da vida cultura, sendo que a letra impressa era o centro da atividade intelectual.

É esse o cenário que os textos nos revelam hoje, com parâmetros de ontem. Como explica Néstor Canclini, "as crônicas jornalísticas de fins do século XIX e princípios do XX configuravam o sentido da vida urbana inventariando o orgulho monumental dos signos de desenvolvimento comercial moderno"30, constituindo a narrativa, por excelência, da modernidade que nascia. Essa modernidade, "cenário de perdas, mas também de fantasias reparadoras”, nas palavras de Beatriz Sarlo ${ }^{31}$, constrói a nova paisagem urbana e fortalece os meios de comunicação. Os periódicos tornam-se instrumentos de intervenção no novo cenário, fazendo com que o impacto dessas transformações seja sentido pela sociedade, que acreditava que "o futuro era hoje".

Para Olavo Bilac, a luxuosa revista Kósmos era paradigmática no que concernia à imprensa do início do século XX. No texto da primeira edição, quando apresentou a revista, escolheu como tema central o papel dos periódicos na vida da sociedade, enaltecendo a importância desta

imensa e dilatada imprensa de informação, que avassala a terra, dirigindo todo o movimento comercial, político e artístico da humanidade, pondo ao

27 BILAC, Olavo. Chronica. Gazeta de Notícias. Rio de Janeiro, 29/07/1906. In: DIMAS, Antônio. Bilac, o Jornalista: crônicas. v.1. op. cit., p.804

${ }^{28}$ Ainda que a autora esteja aqui tratando mais especificamente da a cidade de Buenos Aires, a referência pode ser estendida para o Rio de Janeiro, pois o fenômeno e a experiência da modernização é comum, inclusive contemporânea às duas cidades.

${ }^{29}$ SARLO, Beatriz. Paisagens Imaginárias: Intelectuais, Arte e Meios de Comunicação. op.cit. .p. 203

${ }^{30}$ CANCLINI, Nestor. Consumidores e cidadãos: conflitos multiculturais da globalização. $4^{\mathrm{a}}$. ed., Rio de Janeiro: Ed. da UFRJ, 1999, p.150

${ }^{31}$ SARLO, Beatriz. Buenos Aires, cidade moderna. In: Paisagens Imaginárias: Intelectuais, Arte e Meios de Comunicação. São Paulo: Editora da Universidade de São Paulo, 1997. p.217 
seu próprio serviço, à medida que aparecem, todas as conquistas da civilização, aumentando e firmando de ano em ano o seu domínio, - e chegando a ameaçar de morte a indústria do livro(... $)^{32}$

No mesmo texto apresentou a linha editorial da revista e seus propósitos, no que chama de "programa", exercendo papel de editorialista ${ }^{33}$. "Instalado comodamente" nas primeiras páginas da revista, de 1904 a 1908, “comenta o mundo a seu redor, abordando-o genericamente, exortando-o ao progresso, enaltecendo os avanços técnicos, mencionando explicitamente os dirigentes, quando nos louvores, mas calandose oportunamente, quando na incisão mais funda e decidida ${ }^{34}$. Ainda no texto da primeira edição, ou seja, na sua apresentação aos leitores, afirmou que finalmente o Brasil havia entrado numa fase de revitalização, tendo a higiene, a beleza e a arte encontrado quem as introduzisse no país, fazendo "essa lenta e maravilhosa metamorfose da lagarta em borboleta" 35 . O cronista explicou, ainda, que era projeto da direção da revista acompanhar todas as mudanças desta regeneração moral e material e que esse fato explicava suas presença naquelas páginas.

Eis que a crônica aparece como expressão desse novo tempo e também como sua conseqüência. Pois, ao ser a modernidade múltipla, polifacetada, contraditória, descontínua, como experiência vital, ela pressupõe mais de um olhar, mais de um fazer, mais de um viver. Como gênero moderno que é, a crônica forneceu espaço para se pensar a modernidade como paradoxo, uma vez que é simultaneamente inclusa e estranha aos sujeitos que a criam. O uso dessa múltipla escritura de forma contundente pela primeira vez leva os escritores a escrever, como Ruben Darío, em seu Canto de Vida y Esperanza, que "Yo soy aquel que ayer no más decía/ el verso azul y la canción profana (...) y muy siglo dieciocho y muy antiguo y muy moderno; audaz, cosmopolita; con Hugo fuerte y con Verlaine ambiguo, y una sed de ilusiones infinitas ${ }^{36}$.

Dessa simbiose surgem e se alimentam os escritores modernos, cujas escrituras fundem-se, multiplicam-se e modificam-se. E, se a poesia surge soberana e

${ }^{32}$ BILAC, Olavo. Crônica. Kósmos. Rio de Janeiro: janeiro de 1904 - texto recolhido no arquivo de periódicos da Biblioteca Nacional

${ }^{33} \mathrm{O}$ termo é utilizado por Antônio Dimas ao analisar as crônicas escritas por Bilac para a Kósmos, nas quais "respondia, ainda que involuntariamente, às atribuições de editoralista, explorando de modo opinativo os assuntos do momento". In: DIMAS, Antônio. Tempos Eufóricos - análise da revista Kósmos 1904-1909, São Paulo: Ática, 1983.

${ }^{34}$ DIMAS, Antônio. Tempos Eufóricos - análise da revista Kósmos 1904-1909. op.cit., p. 51

${ }^{35}$ BILAC, Olavo. Crônica. Kósmos. Rio de Janeiro: janeiro de 1904 - texto recolhido no arquivo de periódicos da Biblioteca Nacional

${ }^{36}$ Citado por: ZANETTI, Susana. O intelectual modernista como artista: Rubén Dario. Revista Tempo Social, v. 19 , n. 1. p.4 
independente, não raro um pouco mais avessa aos influxos do cotidiano, a prosa, por sua vez, constitui-se como o grande campo experimental do movimento renovador, admitindo diversas lições e tendências num esforço coerente de integração da e à modernidade. Nas palavras de Angel Rama, "el periodismo fue el terreno donde se dilucidó primero y donde se puso a prueba y donde triunfó el sincretismo artístico". ${ }^{37}$

A consolidação da imprensa, atrelada ao crescente processo de urbanização das cidades, deu ao jornalismo diferentes papéis na vida em sociedade. Já em 1841 Domingos Sarmiento escrevia, ao referir-se à imprensa argentina: "El diário es para los pueblos modernos lo que era el foro para los romanos. La prensa ha sustituido a la tribuna y el púlpito, la escritura a la palabra (...). Por el diarismo el genio tiene por patria al mundo e por testigo la humanidad civilizada"38. Veículos por excelência dos tempos modernos, os periódicos são ainda mais influentes numa sociedade pouco letrada e que vivia na periferia do capitalismo, como a brasileira.

Foram nas crônicas escritas no 'calor da hora' que os jornalistas da virada do século - tendo Bilac, no caso brasileiro, lugar de destaque - revelaram, como em nenhum outro texto, suas impressões sobre a mudanças pelas quais passava a sociedade agora em acelerado processo de urbanização. E, junto com a expansão dos centros urbanos e as mutações dos valores da cultura cotidiana, modificaram-se os próprios padrões da comunicação social.

\footnotetext{
Antigamente, a Imprensa doutrinava, não informava, porque não precisava informar: a época era calma, as gentes eram pacatas e pouco curiosas, a vida era modorrenta. Hoje, a vida é febril, as gentes são ávidas e impacientes, a época é de uma atividade vertiginosa. Cada século tem a sua imprensa. Quando uma cidade se transforma materialmente, também se transforma todo o seu organismo intelectual e moral. O jornal antigo doutrinava, - e tinha cem leitores, o jornal moderno informa - e devora uma bobina de papel por minuto. Aquele não precisava de propaganda, nem de pressa; este, se não progredir incessantemente, morre! $!^{39}$
}

As inovações tecnológicas mudaram a própria consciência do tempo. $\mathrm{Na}$ área da informação, o telégrafo sem fio, a fotografia, o cinematógrafo e as rotativas que produziam milhares de cópias trouxeram a velocidade para o mundo da comunicação. A mesma rapidez foi sentida nas ruas com a chegada do bonde elétrico, do automóvel e com a invenção do avião. O tempo disparou e mudou também a narrativa, como

${ }^{37}$ RAMA, Angel. Ruben Dario y el modernismo. Caracas: Alfadil, 1985. p.79

${ }^{38}$ Citado por ROTKER, Susana. Fundación de uma escritura: las crônicas de Jose Martí. La Habana: Casa de las Américas, 1992. p. 100

39 BILAC, Olavo. Chronica. Gazeta de Notícias. Rio de Janeiro, 10/06/1906 - texto recolhido no arquivo de periódicos da Biblioteca Nacional 
Machado de Assis testemunhou em meados dos anos 90 do século XIX: "não tínhamos ainda esse cabo telegráfico, instrumento destinado a amesquinhar tudo, a dividir novidades em talhadas finas, poucas e breves" ${ }^{, 40}$.

Ao elencar as principais alterações que paulatinamente entravam na imprensa, Werneck Sodré explicitou a nova realidade encontrada por que aqueles homens que faziam as folhas:

Tais alterações serão introduzidas lentamente, mas acentuam-se sempre: a tendência ao declínio do folhetim, substituído pelo colunismo e, pouco a pouco, pela reportagem; a tendência para a entrevista, substituindo o simples artigo político; a tendência para o predomínio da informação sobre a doutrinação; o aparecimento de temas antes tratados como secundários, avultando agora, e ocupando espaço cada vez maior, os policiais com destaque, mas também os esportivos e os mundanos. Aos homens de letras, a imprensa impõe, agora, que escrevam menos colaborações assinadas sobre assuntos de interesse restrito do que o esforço para se colocarem em condições de redigir objetivamente reportagens, entrevistas, notícias. ${ }^{41}$

Ao jornalista, desse momento em diante, caberia a função de reportar os fatos da contemporaneidade com clareza, precisão e contextualização, apartando-se definitivamente do estilo literário. Foi na crônica, então, que se tornou possível fugir da tal objetividade engessadora, castradora. Estabelecendo uma conexão entre o fato e a opinião, com direito ainda a inserir ficção, os cronistas conseguiam expor as narrativas do cotidiano, num exercício contínuo de criatividade, sem deixar de atuarem como testemunhas oculares de seu tempo. São os narradores, que segundo Walter Benjamin, se diferenciam dos que escrevem a história, os historiadores:

(...) a história escrita se relacionaria com as formas épicas como a luz branca com as cores do espectro. Como quer que seja entre todas as formas épicas a crônica é aquela cuja inclusão na luz pura e incolor da história escrita é mais incontestável. E, no amplo espectro da crônica, todas as maneiras com que uma história pode ser narrada se estratificam como se fossem variações da mesma cor. O cronista é o narrador da história ${ }^{42}$

Para Walter Benjamin os novos cronistas conceberam desde uma filosofia do cotidiano uma poética para o século XXI. A linguagem, muito mais coloquial na

\footnotetext{
40 ASSIS, Machado de. A Semana (1894/1895), Rio de Janeiro: Jackson, 1959. Citado por: VELLOSO, Mônica Pimenta. Modernismo no Rio de Janeiro: turunas e quixotes. Rio de Janeiro: Fundação Getúlio Vargas, 1996, p.23.

41 SODRÉ, Nelson Werneck. História da imprensa no Brasil. $4^{\mathrm{a}}$ ed. Rio de Janeiro: Civilização Brasileira, 1976, p.339

42 BENJAMIN, Walter. Magia e Técnica, arte e politica - ensaios sobre a literatura e história da cultura. Obras escolhidas. Vol. 1. São Paulo: Brasiliense 1986, p.209
} 
crônica, não dispensa a fruição estética. Para o filósofo alemão, o texto em crônica ressalta a valorização da experiência justamente por corresponder a uma época em que a experiência ( Erfahrung) foi obnubilada pela vivência (Erlebnis) ${ }^{43}$. Fruto do isolamento, da perda da comunidade, a crônica, visto se encravar na percepção individual, talvez por isso tenha alcançado tamanha aceitação. Precisamente porque a crônica não tem pretensão de história é que se torna capaz de extrair dimensões significativas dos tempos idos, o que dá oportunidade para que "o passado, conservando o sabor do fantasma, recuperará a luz e o movimento da vida, e se tornará presente ${ }^{34}$.

Pela sua inerente ambigüidade, a crônica documenta para sempre, à parte a transitoriedade do veículo, transformando o autor numa espécie de historiador do cotidiano. O gênero deixa registrado instantes preciosos do passado, escritos quando eram fatos do presente. Precursora da historiografia, "a crônica pode constituir o testemunho de uma vida, o documento de toda uma época ou um meio de se inscrever a história no texto". ${ }^{45}$ Foi para essa linha que Olavo Bilac apontou quando propôs que seus pares fossem obrigados a reler todos os textos ao final de cada ano para então:

\begin{abstract}
resumi-las numa página sintética, escrevendo assim, para uso e edificação da posteridade, a história de cada período de doze meses; no fim de um decênio, as dez crônicas, resumidas anualmente, seriam ainda apertadas e espremidas em uma só crônica; ao cabo de um século, um historiador trituraria no almofariz da sua crítica os elementos das dez histórias decenais, e assim estariam escritos, sem grandes trabalhos, os fastos da civilização. ${ }^{46}$
\end{abstract}

Ainda que não tenha surgido para durar, por ser "filha do jornal e da era da máquina" 47 , pode ser considerada como documento por expressar um tempo social, tecendo as novidades da sociedade que se movimenta. ${ }^{48}$ Entre as tantas inovações surgidas no mundo moderno de então, inscreveu-se a imprensa e nela o mais novo gênero literário difundido e aceito. Constituiu-se um texto que condensa na letra o

43 BENJAMIN, Walter. Magia e Técnica, arte e política - ensaios sobre a literatura e história da cultura. Op. cit,.p. 165

${ }^{44}$ BAUDELAIRE, Charles. Sobre a modernidade.op.cit.p. 27

${ }^{45}$ ARRIGUCCI JUNIOR, Davi. Enigma e comentário: ensaios sobre literatura e experiência, op.cit., p 52

${ }^{46}$ BILAC, Olavo. Ironia e Piedade. Rio de Janeiro, Francisco Alves, 1916, p. 200

${ }^{47}$ CANDIDO, Antonio (et al). A crônica: o gênero, sua fixação e suas transformações no Brasil, op.cit., p. 14

${ }^{48}$ NEVES, Margarida de Souza. Um escrita no tempo: memória, ordem e progresso nas crônicas cariocas. In. CANDIDO, Antonio (et al). A crônica: o gênero, sua fixação e suas transformações no Brasil, op.cit., p.76 
tempo vivido ${ }^{49}$, sendo construção e também interpretação do real. Nas palavras de Raúl Antelo, "volúvel e heterogênea, a crônica, enquanto gênero, não deveria ser vista como um repertório de invariantes formais ou temáticas, mas como um campo estruturado de tensões simbólicas e imaginárias, históricas e estéticas" ${ }^{50}$. Esse campo encontrou terreno fértil nas páginas periódicas e transforma os acontecimentos diários na sua matériaprima privilegiada, fazendo do imponderável do cotidiano material de trabalho e, "de repente, naquela linguagem volátil, se encontrava terra-a-terra com a poesia cotidiana" $^{51}$.

É de fundamental importância também seu papel como renovadora da linguagem empolada que vigorava na imprensa e na literatura do século XIX, tornando-se uma escrita dos novos tempos, uma "coisa moderna no jornalismo e na literatura, pois participa de ambos", como afirmou José Veríssimo ${ }^{52}$. Ao comentar e analisar os fatos sociais através de um texto cotidiano, operou "milagres" de significação, como explicou Antonio Candido, citando como exemplar o caso de Olavo Bilac:

\begin{abstract}
A leitura de Bilac é instrutiva para mostrar como a crônica já estava brasileira, gratuita e meio lírico-humorística, a ponto de obrigá-lo a amainar a linguagem, a descascá-la dos adjetivos mais retumbantes e das construções mais raras, como as que ocorrem na sua poesia e na prosa de suas conferências e discursos. Mas que encolhem nas suas crônicas. É que nelas parece não caber a sintaxe rebuscada, com inversões freqüentes; nem o vocabulário 'opulento', como se dizia, para significar o que era variado, modulando sinônimos e palavras tão raras quanto bem soantes. Num país como o Brasil, onde se costuma identificar superioridade intelectual e literária com grandiloqüência e requinte gramatical, a crônica operou milagres de simplificação e naturalidade. ${ }^{53}$
\end{abstract}

\title{
REFERÊNCIAS
}

ARRIGUCCI JUNIOR, Davi. Enigma e comentário: ensaios sobre literatura $e$ experiência. São Paulo: Companhia das Letras, 1987

BAUDELAIRE, Charles. Sobre a modernidade. $3^{\mathrm{a} e d .}$ Rio de Janeiro: Paz e Terra, 2002.

\footnotetext{
${ }^{49}$ DIOGO, Marcia Cezar. O moderno em Revista na cidade do Rio de Janeiro. In: CHALHOUB, Sidney (et al). História em cousas miúdas: capitulos de história social da crônica no Brasil, p.462.

50 ANTELO, Raúl. João do Rio = Salomé. In: CANDIDO, Antonio (et al). A crônica: o gênero, sua fixação e suas transformações no Brasil, op.cit., p. 155.

${ }^{51}$ ARRIGUCCI Jr. Davi.In: BRAGA, Rubem. Os melhores contos de Rubem Braga. São Paulo: Global, 1985.

52 VERÌSSIMO, José. Últimos estudos de literatura brasileira: $7^{a}$ série. Belo horizonte: Ed. Itatiaia; São Paulo: EDUSP, 1979, p.127

53 CANDIDO, Antonio (et al). A crônica: o gênero, sua fixação e suas transformações no Brasil, op.cit., p.16
} 
BENJAMIN, Walter. A modernidade e os modernos. Rio de Janeiro: Editora Tempo Brasileiro, 1975.

Magia e Técnica, arte e política - ensaios sobre a literatura e história da cultura. Obras escolhidas. Vol. 1. São Paulo: Brasiliense, 1986.

BERMAN, Marshall. Tudo que é sólido desmancha no ar: a aventura da modernidade. São Paulo. Cia das Letras, 1986.

BILAC, Olavo. Ironia e Piedade. Rio de Janeiro, Francisco Alves, 1916.

CANCLINI, Nestor. Consumidores e cidadãos: conflitos multiculturais da globalização. 4ª . ed., Rio de Janeiro: Ed. da UFRJ, 1999.

CANDIDO, Antonio (et al). A crônica: o gênero, sua fixação e suas transformações no Brasil. Campinas: Ed. da UNICAMP; Rio de Janeiro: Fundação Casa de Rui Barbosa. 1992

CHALHOUB, Sidney (et al). História em cousas miúdas: capitulos de história social da crônica no Brasil. Campinas: Ed. da UNICAMP, 2005.

CHIAMPI, Irlema (coord). Fundadores da Modernidade. São Paulo: Editora Ática, 1991.

COMPAGNON, Antoine. Os cinco paradoxos da modernidade. Belo Horizonte: Editora da UFMG, 1996.

DIMAS, Antonio (Org.) . Vossa Insolência. Crônicas de O. Bilac. São Paulo: Companhia das Letras, 1996.

DOMINGOS, Chirley; ALVES, Marcelo (orgs). A cidade escrita - literatura, jornalismo e modernidade em João do Rio. Itajaí: Universidade do Vale do Itajaí, 2005. FISCHER, Luís Augusto. Parnasianismo brasileiro: entre ressonância e dissonância. Porto Alegre: Edipucrs, 2003.

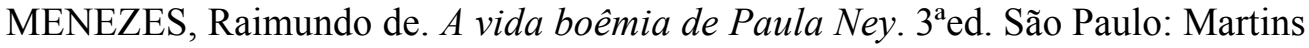
Editora, 1957.

NEEDELL, Jeffrey. Belle Époque Tropical: sociedade e cultura de elite na virada do século. São Paulo: Companhia das Letras, 1993.

PESAVENTO, Sandra. O imaginário da cidade: visões literárias do urbano - Paris,

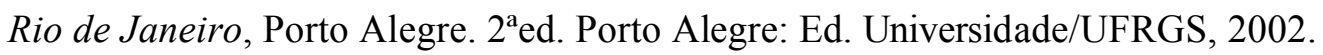

RAMA, Angel. Ruben Dario y el modernismo. Caracas: Alfadil, 1985.

ROTKER, Susana. Fundación de uma escritura: las crônicas de Jose Martí. La Habana: Casa de las Américas, 1992. 
SARLO, Beatriz. Paisagens Imaginárias: Intelectuais, Arte e Meios de Comunicação.

São Paulo: Editora da Universidade de São Paulo, 1997.

SIMÕES JR., A. S. A sátira do parnaso. Tese de Doutorado. PPGL. Assis: UNESP, 2001.

SODRÉ, Nelson Werneck. História da imprensa no Brasil. $4^{\mathrm{a}}$ ed. Rio de Janeiro: Civilização Brasileira, 1976.

SOUZA, Célia Ferraz de; Pesavento, Sandra Jathay (org). Imagens urbanas: os diversos olhares na formação do imaginário urbano. Porto Alegre: Editora da Universidade, 1997.

VELloso, Mônica Pimenta. Modernismo no Rio de Janeiro: turunas e quixotes. Rio de Janeiro: Fundação Getúlio Vargas, 1996.

VERÌSSIMO, José. Últimos estudos de literatura brasileira: $7^{\text {a }}$ série. Belo horizonte: Ed. Itatiaia; São Paulo: EDUSP, 1979.

ZANETTI, Susana. O intelectual modernista como artista: Rubén Darío. Revista Tempo Social, v. 19, n. 1. 